\title{
Workflow Re-engineering for Implementing a 4D Construction Management Tool in a Design-Build Project
}

\author{
Meng-Han Tsai ${ }^{1}$, Abdul Matin Md², Shih-Chung Kang ${ }^{3}$, Shang-Hsien Hsieh ${ }^{4}$ \\ ${ }^{1} \mathrm{PhD}$ student, Computer-Aided Engineering Group, Department of Civil Engineering, National Taiwan \\ University, Taipei, Taiwan; PH (886) 2-3366-4342; FAX (886) 2-2368-8213; e-mail: d9521002@ntu.edu.tw \\ ${ }^{2}$ Civil Engineer and Research assistant, Computer-Aided Engineering Group, Department of Civil \\ Engineering, National Taiwan University, Taipei, Taiwan; PH (886) 2-3366-4342; FAX (886) 2-2368-8213; e- \\ mail:matin.pwd@gmail.com \\ ${ }^{3}$ Assistant Professor, Computer-Aided Engineering Group, Department of Civil Engineering, National \\ Taiwan University, Taipei, Taiwan; PH (886) 2-3366-4346; FAX (886) 2-2368-8213; e-mail: \\ kang@ntu.edu.tw \\ ${ }_{4}^{4}$ Professor,Computer-Aided Engineering Group, Department of Civil Engineering, National Taiwan \\ University, Taipei, Taiwan; PH (886) 2-3366-4313; FAX (886) 2-2368-8213; e-mail: shhsieh@ntu.edu.tw
}

\begin{abstract}
The use of 4D management tool in construction industry has been growing rapidly in recent years in response to soaring demands on efficient construction management. Successful implementation of this tool in an engineering firm for use in real projects is still challenging. This paper shares the experience on implementing an in-house 4D management tool in a large EPC (Engineering, Procurement and Construction) firm that has extended reputation on design-build projects. A new workflow was proposed that takes full advantage of the 4D tool to enhance construction management performance and minimizes impacts on the firm's existing workflow. The workflow development for the firm to implement 4D management tool in real project was done by interviewing key personnel in multiple departments of the firm and by carefully examining probable impacts of the 4D tool's introduction into the firm's business processes.
\end{abstract}

Keywords: 4D management tool, design-build, workflow.

\section{Introduction}

4D visualization technology, the four-dimensional planning and scheduling that binds 3D models with their corresponding construction work schedule in its simplest form, has emerged rapidly (Hsieh et. al., 2006) in the past decades in construction and project management framework. This is mainly due to the increasing recognition from the construction industry of the benefits of using the 4D CAD applications (Kam et. al., 2003; Dawood et. al., 2003; Heesom and Mahdjoubi, 2004). The benefits of using 4D modeling mechanisms compare to the traditional tools are well described in several researches over time for its increased productivity, improved project coordination capability and optimized on-site resource utilization techniques etc. 4D construction management tools have experimentally been deployed in many projects in recent years. San Mateo Health Facility (Collier and Fischer, 1996) and Construction Director (Hsieh et al., 2006) are two brilliant examples among them.

Although many firms in construction industry realized the benefits of 4D tool, the decision-makers nevertheless are not confident enough in adopting this new tool for real project. A pragmatic application of this tool in practical business process is very much important towards its successful implementation in actual project. This research addresses this issue by intelligently developing company's existing workflow. This approach was carefully adopted towards successful application of "Construction Director", a well-defined 4D management tool developed by NTU (National Taiwan University) in collaboration with CTCI Corporation, Taiwan. Development of Construction Director has been summarized in a paper previously authored by Hsieh et al. (2006). The design of "Construction Director" takes advantages of several design patterns that could satisfactorily display and convey construction information with the $3 \mathrm{D}$ model and the work items on the daily schedule (Tsai et. al., 2008). In addition, the work plan in phase can be displayed and distinguished with different colors (Chang, et. al., 2007). Based on the current system (3D model by using 
"Smart Plant Review" software) the tools and interfaces in "Construction Director" are developed to facilitate the four-dimensional construction simulations.

We selected a design-build project of CTCI Corporation, the largest engineering, procurement and construction (EPC) firm in Taiwan and one of the top 200 contracting companies in the world, as a case study. We experimentally implemented "Construction Director" (4D tool) in place of 3D reviewing tool in their existing workflow. SPR (Intergraph Smart Plant Review) has been used in CTCI for more than a decade. We observed impact of the use of SPR and "Construction Director" respectively on the existing workflow of the company and the proposed workflow re-engineered by us. After multiple interviews with the personnel of different engineering departments of CTCI, each step of the set-up workflow was carefully adjusted according to the management demands by minimizing changes to the existing workflow. We focused on how the firm used 3D reviewing tools in their existing workflow to facilitate the design and construction process and then proposed a customized workflow that introduced 4D tool (i.e. Construction Director). The approaches for the introduction of 4D tool into company workflow that this paper presents might very well be effective to help more professional use of this tool in real project.

\section{Workflow Re-engineering Approach}

Based on the information obtained from the interviews, we observed impact of the use of SPR and "Construction Director" respectively on the existing workflow of the company and the proposed workflow re-engineered by us. We adopted the following procedures to do that.

\section{The interviews}

We conducted interviews to relevant engineering personnel of different departments of CTCI, which were divided into two stages. At the first stage, we arranged a half day interview with the manager of the design department and obtained an overview of the existing workflow of a design-build project of CTCI. As the manager had been involved in the development of Construction Director (4D tool), we obtained his views for the new workflow and identified the redistribution of responsibilities among the departments after introducing the 4D tool in the existing workflow. Based on the information obtained from the first stage interview, we drafted two figures illustrating the existing workflow and the modified (proposed) workflow respectively. Then we conducted the second stage interview whereby two interviews were taken place.

At the second-stage interviews, the first one was to interview the manager of the project management department. We asked him to review the figures of the workflows we already had drafted and to confirm the roles and responsibilities of his department in both the workflows. The second interview of this stage was held in construction department with three personnel that included the manager, a senior engineer and the human resource engineer. We asked them to review workflow figures and to point out inappropriate part by concentrating on their relevant sector in the workflow, particularly the communication with sub-contractors, the inter-departmental interactions and other concerned issues during construction processes.

After the interviews, we incorporated their views and suggestions and carefully examined the possible impacts of the 4D tool's introduction into their business processes and then developed the final workflow.

\section{Symbols used in the workflow}

Table 1 depicts the symbols used in the workflows. The arrowhead represents the flow direction of data/operation. The solid arrowhead represents one-to-many relationship and the non-solid arrowhead represents a zero relationship between the work items. We also used two dash arrowheads to represent the data exchange in either forward or backward operations. The work items are presented in rectangular boxes. The shaded rectangular boxes represent the work items associated with the 4D tool (Construction Director) that is shown only in Figure 2. The diamond box represents flow judgment. Round-edged dash line rectangle is for cooperation block that represents interaction, communication, negotiation and understanding between the departments. The sharp-edged dash line rectangle is for recursive operation that needs to be performed repeatedly until the goals have been achieved.

\section{Existing Workflow}

After the interviews, we produced a typical workflow to CTCI using the symbols explained above. As shown in Figure 1, the owner announces the initial requirements at the very outset of the project. These 
requirements include owner's budgetary limit, time allowance, particular objectives, expectations, limitations, and regulatory specifications etc. CTCI, as a contracting company, confirms owner's award to execute the design-build project and starts developing a project plan. Then prepares deliverables in accordance with the owner's demand and guidelines, and submit it to the owners for their concurrence. Usually owners would review the project plan proposed by CTCI and then ask CTCI to explain and redefine it several times if it does not satisfy their criteria and expectation. Upon achieving satisfaction with project plan, owners would award the final contract to CTCI to commence construction. Engineers of design department of CTCI then create a 3D model according to the plan proposed earlier to owner. Using the model, they recursively perform structural analysis and parameter study. In Figure 1, this process is presented by a recursive block. Finally, a set of necessary construction drawings are prepared to support work items and activities of the project.

Table 1 Diagrams of work items

\begin{tabular}{cccc}
\hline Diagram & Representation & Diagram & Representation \\
\hline & $\begin{array}{c}\text { Data flow/operation } \\
\text { (one to many) } \\
\text { Construction } \\
\text { Director(4D tool) }\end{array}$ \\
\hline & $\begin{array}{c}\text { Data flow/operation } \\
\text { (zero) }\end{array}$ & Judgment \\
\hline & $\begin{array}{c}\text { Date exchange } \\
\text { /operations both way }\end{array}$ & Cooperation block \\
\hline & Work item & Recursive block \\
\hline
\end{tabular}

In the design and construction phases, CTCI usually has to lead through three major milestones in their existing workflow that includes inter-departmental meetings and owner's review for handling the design details, materials procurement and construction details. All these three landmarks need involvement of engineering personnel from different departments and concurrence of clients to effectively solve construction issues. Both the conferences and reviews rely heavily on the 3D model developed by design department of CTCI. The 3D model is usually displayed on a large screen. The concerned engineers from different departments review their individual parts regarding plan, schedule, cost and budget, site planning, manpower deployment, owner's review etc in the 3D model. Project department of CTCI usually plays coordinating role to resolve conflicts among the departments. Review of 3D model by the owner is required to achieve a final decision for further proceed. At the same time, interpreting of construction schedule and understandings of other relevant issues are needed to be clarified to the owner. Since most of the owners of CTCI do not have strong construction background, they usually hire in-house construction professionals to help them understand the project issues clearly. The owner and the project management unit monitor the quality and progress of the construction, based on the 3D model and the construction plan developed in the design phase. The site departments, including the schedule control, procurement, construction department and the sub-contractors perform construction activities according to the 3D model and the construction plan. The workflow is depicted in figure 1.

\section{Proposed Workflow}

We finally proposed a modified workflow that incorporates 4D tool (Construction Director) in the existing workflow of CTCI. The proposed workflow is presented in Figure 2. We minimized changes to the existing workflow, which will reduce the possibility of unforeseen impact on the organizational structure and on the working processes they were used to. Unlike using 3D model to review the construction plan, the engineers will use Construction Director, the 4D management tool as the major reference in the proposed 
workflow during their inter-departmental meetings. They also can use this tool to explain and present the plan and design results with project progress to the owners.

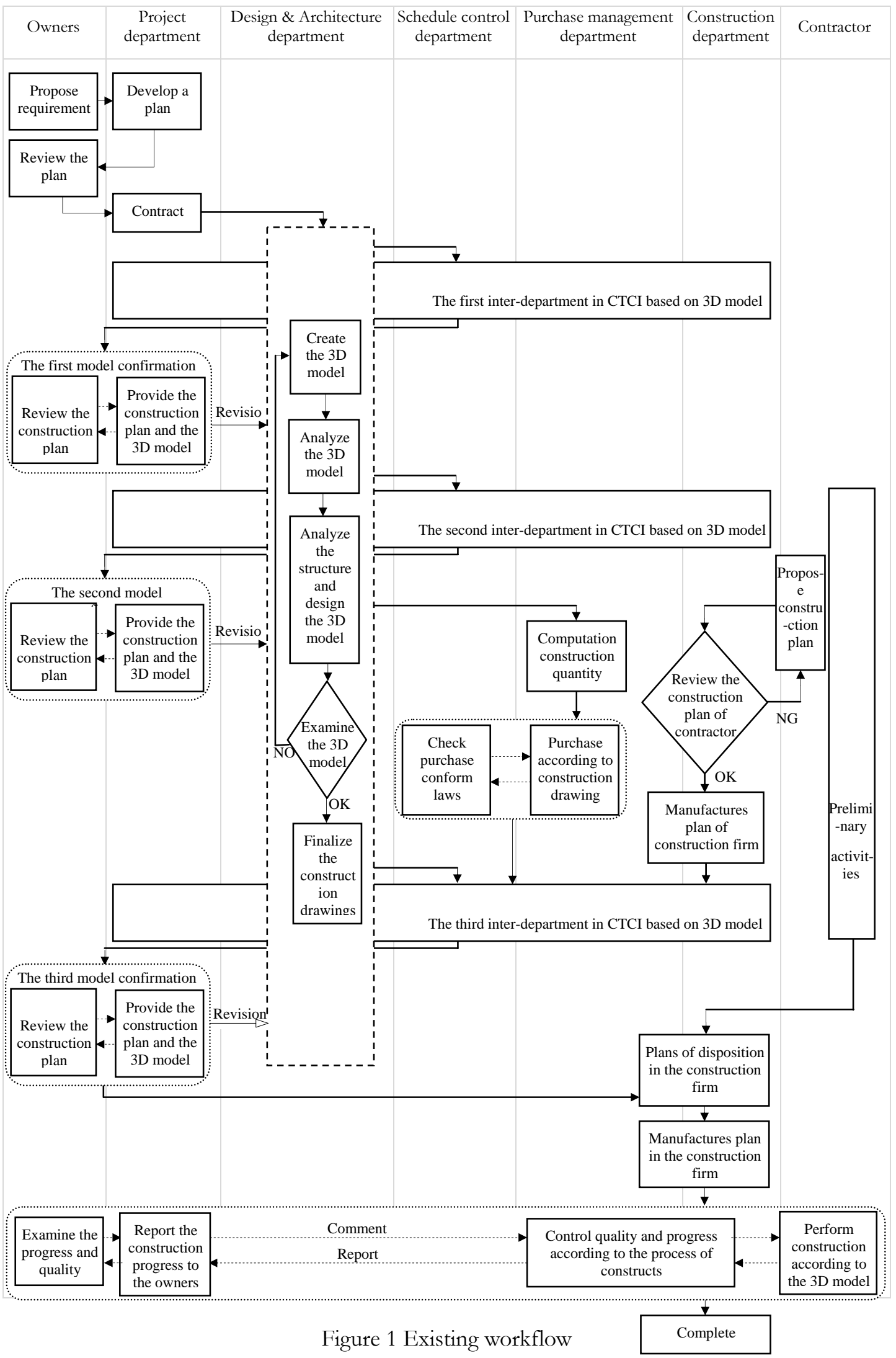


The following paragraph summarizes the major advantages of the proposed workflow on top of the existing workflow. Firstly, the 4D model tool plays a vital role in the inter-departmental meetings of the company. These models are created by using $3 \mathrm{D}$ models and the schedule that presents the construction progresses visually. Therefore, 4D model can successfully reduce a large amount of time wasted for explanation and clarification of construction issues in the meetings. Secondly, 4D tool can appreciably be used in the owners' review. This will assist them in locating problems from the user's point of view and will help in making decisions with firm confidence. Thirdly, this intelligent tool can very well be used in construction sites. For a design-build project, one major concern is the communication amongst subcontractors, especially among them who work in close proximity of schedule conflicts. As well, the main contractor has to communicate and liaise with many specialized technologists, suppliers and regulating agencies with regard to execution of construction activity, material storage, access point, transport, permits and safety issues etc. It provides engineers with a more direct approach to obtain the information on hand to trace the predecessors and successors of each construction activity to avoid clashing of operations. Thus the engineering manager and the site engineers can easily take offhand decisions relating to site matter with more confidence. 4D tool also helps identify accessibility issues of movable equipment such as trucks, excavators, concrete pumps, mobile crane, gantry crane etc. and the arrangements of stationary equipment such as tower cranes, pump stations, boring machines etc. Therefore, it must improve the communication excellence between the parties involved in project works and positively enhance performances of the entire project to harmonize the operations.

\section{Comparison between Existing Workflow and Proposed Workflow}

As described in Table 2, we compare the existing workflow with the proposed workflow from two aspects. In the existing workflow engineers maintain the 3D model in their inter-departmental conferences and project review meetings. Their means of correspondence were the 3D model and the project schedule in a separate stature to devise project plan. This would be hard to facilitate engineers and the owner to understand the optimal productivity of the project prior to construction. Moreover, when different departments present their individual assignments in project coordination meetings, they ought to present the 3D model and the schedule in detail. This is a jeopardized system in communication and coordination perspective, especially if it is a large project.

In the proposed workflow, we introduced 4D construction management tool to resolve the uncertainty and ambiguity of the project matters. After introducing 4D tool, the physical constraints of site could be visualized, as well as the conflicts of concurrent activities could be identified to avoid coexistence of multi operations in one point. Therefore, the schedule controller (planning engineer) can synchronize the progress according to the accomplishment of the construction and can give immediate feedback towards organizing/reorganizing the works. And the project participants can beforehand make arrangement of procurement, equipment, manpower, exact bill of quantities etc.

According to the feedback obtained from the interviews, the operational mode of CTCI is transferred from traditional model to current 4D model. The changes showed the 3D model couldn't absolutely satisfy the company needs, thus 4D tool (Construction director) was introduced.

\section{Conclusions}

This paper presents a workflow proposed specifically for using 4D models in design-build projects. We selected a large EPC firm with an in-house 4D tool as an example case. By interviewing the key persons from different departments, we summarize the existing workflow in that firm. From the workflow, we found that the owners and engineers from different departments rely mainly on 3D models and paper-based schedule to communicate and manage the project. We proposed a new workflow for the firm, in which 4D models become facilitating tool to increase the communication between the owners and the engineers from different departments. We expect the proposed workflow can increase the degree of satisfaction from the owner, better the teamwork amongst concerned departments and eventually raise company's competitiveness in the market. 


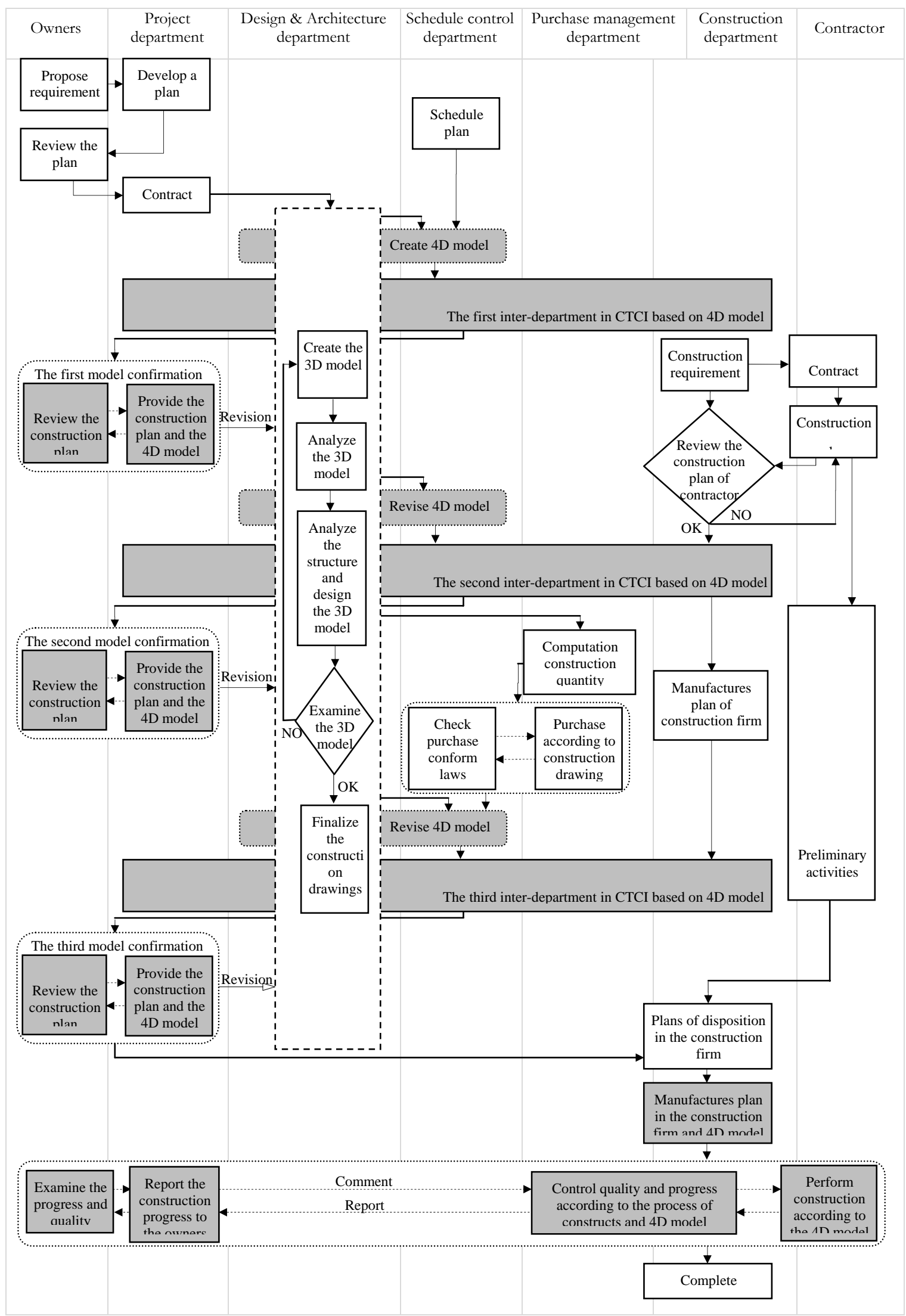

Figure 2 Proposed workflow 
Table 2 The comparison of activities

\begin{tabular}{|c|c|c|}
\hline Workflow & Internal Communication & External Communication \\
\hline $\begin{array}{c}\text { Existing } \\
\text { workflow } \\
\text { (3D) }\end{array}$ & $\begin{array}{l}\text { 1. Engineers maintain the 3D model. } \\
\text { 2. Presenting 3D model and schedule need more } \\
\text { activities thus require additional time to interpret. } \\
\text { 3. Communication, coordination for team work is } \\
\text { difficult. } \\
\text { 4. Unable to use 3D model in different departments } \\
\text { to know construction progress. } \\
\text { 5. Can't efficiently plan equipment, manpower etc. }\end{array}$ & $\begin{array}{l}\text { 1. Owner doesn't } \\
\text { understand project } \\
\text { issues clearly. } \\
\text { 2. Information gaps } \\
\text { existed. } \\
\text { 3. Communication gaps } \\
\text { may exist. }\end{array}$ \\
\hline $\begin{array}{l}\text { Proposed } \\
\text { workflow } \\
\text { (4D) }\end{array}$ & $\begin{array}{l}\text { 1. Engineers maintain the 4D model. } \\
\text { 2. Managing the schedule with 4D model can } \\
\text { control complex project easily. } \\
\text { 3. Personnel can beforehand make arrangement of } \\
\text { equipment, manpower, procurement etc. } \\
\text { 4. Presenting individual department's issue is easier, } \\
\text { thus facilitates communication and coordination. }\end{array}$ & $\begin{array}{l}\text { 1. Report project plan } \\
\text { with } 4 \mathrm{D} \text { model. } \\
\text { 2. Owner can understand } \\
\text { project related issues. } \\
\text { 3. Visualization process } \\
\text { helps in conveying } \\
\text { information. }\end{array}$ \\
\hline
\end{tabular}

\section{Acknowledgement}

Financial support from CTCI Foundation is gratefully acknowledged. The authors would like to thank Mr. Yuan-Fu Liao of CTCI Corporation, Prof. Chuin-Shan Chen and Mr. Cheng-Han Kuo of National Taiwan University for their assistance in the development of the 4D construction management tool. We like to express our appreciation to the interviewees of CTCI.

\section{References}

[1] Chang, H.S., Kang, S.C. and Hsieh, S.H. (2007). "Color schemes in 4D construction management tools," Proceedings of Computing in Civil Engineering, Pittsburgh, U.S.

[2] Collier, E. and Fischer, M. (1996). "Visual-based scheduling: 4D modeling on the san mateo county health center," Proceedings of the Third Congress on Computing in Civil Engineering. Anaheim, CA.

[3] Dawood, N., Eknarin, S., Zaki, M. and Brian, H. (2003). "Development of an integrated resources base for 4D/VR construction process simulation and visualization," Automation in Construction, 12(2), 123-131.

[4] Heesom, D. and Mahdjoubi, L. (2004). "Trends of 4D CAD applications for construction planning," Construction Management and Economics, 22(2), 171-182.

[5] Hsieh, S.H., Chen, C.S., Liao, Y.F., Yang, C. T. and Wu, I.C. (2006). "Construction director: 4D simulation system for plant construction," Proceedings of the 10th East Asia-Pacific Conference on Structural Engineering and Construction (EASEC-10), Bangkok, Thailand.

[6] Kam, C., Fischer, M., Hänninen, R., Karjalainen, A. and Laitinen J. (2003). "The product model and fourth dimension project," Journal of Information Technology in Construction, Vol. 8, 137-166.

[7] Liao, Y. F., Hsieh, S. H., Kang, S. C., Chen, C. S., Yang, C. T., Chi, H. L., Chi, W. C. and Yu, C. H. (2007). "Development and application of 4D construction simulation tools," Proceedings of The Fourth Civil Engineering Conference in the Asian Region (CECAR), Taipei, Taiwan.

[8] McKinney, K., Kim, J., Fischer, M. and Howard, C. (1996). "Interactive 4D-CAD," proceedings of the third congress on computing in civil engineering. Proceedings of Anaheim, CA, USA.

[9] Tsai, M. H., Kang, S. C., Hsieh, S. H., Kuo, C. H., Pei, T. J. and Yeh, K. C. (2008). "Experiences on study of setting-up a 4D construction management tool in a high-rise construction project," Proceedings of 12th International Conferences on Computing in Civil and Building Engineering \& 2008 International Conference on Information Technology in Construction (ICCCBE XII \& INCITE 2008), Beijing, China. 